\title{
Luxury During the Epidemic: The Rise of the Chinese Market
}

\author{
${ }^{1}$ Vanderbilt University, Nashville, Tennessee, 37235 \\ *Corresponding author.Email:lizongyu127@gmail.com
}

Zongyu Li

\begin{abstract}
The sudden outbreak of the epidemic has caused a huge economic blow to the world, as various industries have stalled without any preparation. The same goes for the luxury industry, which has suffered a significant loss from stagnant tourism, retails, and marketing activities. Hence, by analyzing the sales situation and marketing strategies of the luxury market from 2010 to 2020, this research mainly discusses the consumption trend of the luxury market after the epidemic from two aspects. On the one hand, luxury brands still need to wait for a long time to recover overseas markets, and re-measure their real consumption value after the epidemic. On the other hand, the Chinese luxury market is experiencing a consumption revolution brought by the pandemic, which may exert a lasting impact on the consumption habits of Chinese consumers in the long term. This study found that the Chinese luxury market has effectively promoted the return of consumption through the duty-free store policy to enlarge the domestic market size. To attract Generation $\mathrm{Z}$ and returning middle-class customers who have great consuming potential in the Chinese luxury market, luxury brands need to create a multi-channel sales approach and carry out diversified, localized, and digital marketing strategies to achieve sustainable development.
\end{abstract}

Keywords: luxury market, China, pandemic, COVID-19

\section{INTRODUCTION}

Due to the attack of the coronavirus in 2020, luxury brands need to find new growth points to recover the economic losses in their global recession. Due to China's excellent epidemic prevention, the high rise of China's luxury goods market has sparked industry-wide concern. The rapid recovery of China's luxury market is closely related to the changes in the global luxury market. The current research on the luxury goods market is derived from the business analysis of consulting companies, which mostly aims at specific customer segments and limited markets instead of a comprehensive analysis of the global market. Therefore, the author explores and compares the changes of the overseas market and Chinese market during the epidemic to explain the miracle recovery of the Chinese luxury market. The first part of the research mainly points out significant shortcomings exposed in overseas markets during the epidemic, which tend to exert a long-lasting influence on the luxury industry. Secondly, the study analyzes the main reasons for the boom in the Chinese luxury market. Through both domestic and overseas market analysis, the research shows the development trend and long-term vision of the luxury goods industry after the epidemic.

\section{THE COLLAPSE OF THE OVERSEAS MARKET}

With the recurrence of the epidemic, the global luxury market has become quite uncertain. The negative impact of many long-standing but unappreciated problems have emerged, such as excessive industry iteration, unavailable fashion shows, dependence on single supply channels, and fraudulent sales in the global market, concerning the survival of the overseas luxury market. The escalation of the coronavirus has delayed the resolution of these problems, shrinking the global luxury market constantly.

\subsection{Out-of-control Industry Rhythm}

The luxury market has been known for its frantic pace of iteration for a long time. After leaving Dior in 2015, Raf Simons said he had long been exhausted because of the intense schedule and workload, leaving 
him with little time for creative thinking. As an essential showcase and marketing channel, the seasonal fashion weeks have been the highlight of the fashion industry. To prepare for the fashion week, it is common knowledge that not only the designing team suffers from the huge work pressure, but also the related merchandising team, marketing teams, and media are all busy around the fashion week system.

However, since the proliferation of material production, luxury brands have filled their year-round schedules with the release of the resort and Haute Couture collections. The rhythm of the fashion industry has evolved from a seasonal to a monthly basis for continuous marketing and exposure to please consumers. Luxury brands are well aware that they are riding on a speeding train which is of great potential to stall and crash in the next moment, overdrawing their customers' passion for consumption. Now, as the epidemic has arrived out of nowhere, the fashion industry has come to an instant halt and shutdown, leaving luxury brands in launching and promotional disaster. With the absence of the fashion week, brands were desperate for alternative platforms to launch and promote their products, maintaining the exposure. The lack of alternative promotional options instantly crushed the expectations of overseas luxury consumers.

\subsection{The Disappearance of Chinese Surrogate Shoppers}

Chinese surrogate shoppers buy products overseas and sell them to mainland customers to make a profit, and they usually avoid tariffs through various channels to save cost. The primary commodities purchased by surrogate shoppers are luxury goods. According to a report by Bain Company, the size of the luxury goods buying industry ranged from RMB 55 billion to RMB 75 billion in 2014, which was almost half of the sales of luxury stores in mainland China [1]. Furthermore, approximately $70 \%$ of Chinese consumers admitted to using surrogate shoppers, resulting in a 7-8 times increase in the surrogate shopping market from 2010 to 2014.

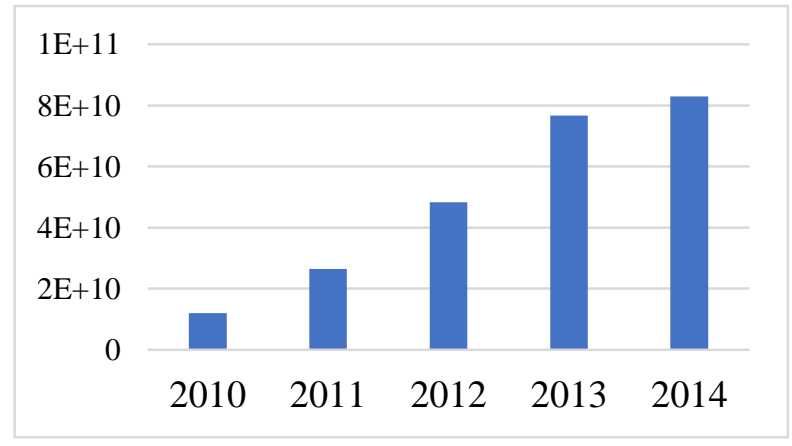

Figure 1: Surrogate Shopping Sales Amount in China
The surrogate shopping industry was started around 2005. International students or people who work abroad utilize the pricing difference of luxury goods to earn profits. According to the Chinese Fortune Character Institute, Chinese consumers bought nearly 46 percent of the world's luxury goods in 2016, reaching 120.4 billion U.S. dollars, a large part of which did not come from China's local luxury stores but the overseas market behind the surrogate shoppers [2]. Using Australia as an example, the Chinese community in Australia is currently about 1 million people, with at least about 5 percent (i.e., 50-60,000 people) engaged in surrogate shopping industries. The Australian surrogate shoppers "exported" up to $\$ 600$ million worth of products to China. Hence, it is fair to say that surrogate shoppers feed a large part of the overseas luxury market.

However, due to negative factors brought by the epidemic, such as reducing flights, the slowdown of cross-border logistics, and the return of many overseas Chinese to their home countries, the surrogate shoppers gradually disappeared from the overseas luxury stores. The disappearance of surrogate shoppers has dealt a severe blow to overseas markets, especially the luxury markets in Europe, America and Japan, and Korea. For example, several duty-free stores have been withdrawn from Korea since February 2020. Moreover, luxury brands need to realize that the depression of the overseas market caused by the disappearance of duty-free is likely not temporary. With the development of duty-free stores within China, Chinese consumers are gradually abandoning the option of buying through surrogate shoppers. Therefore, it is necessary for luxury brands to clearly realize that their future strategies around Chinese consumers have to consider the changing shopping preferences and habits of consumers during the epidemic.

\section{THE RISING CHINESE MARKET}

The impact of the outbreak continues to reverberate through the industry. While the U.S. and Europe will need more time to recover, China, which is well-proofed against the epidemic, is experiencing a solid recovery. According to the report from Bain Company, unlike the backdrop of a $23 \%$ contraction of the global luxury market in 2020, luxury consumption within China rose 48\%, reaching RMB 346 billion. In just one year, the size of the Chinese luxury market has increased from $11 \%$ to $20 \%$ of the global market share. It is expected that in another five years, China may become the largest luxury market in the world [3]. As the policy of duty-free stores unfolds, the situation of Chinese luxury consumption outflow is gradually reversed, making the profit of the Chinese luxury market clearer and more attractive. Hence, luxury brands have begun to abandon their inherent reserve, 
adopting several localized and digital marketing approaches to satisfy Chinese consumers.

\subsection{Development of Domestic Duty-free Shops}

With the stagnation of global tourism influenced by the coronavirus, it is undoubted that Hainan's duty-free store policy has promoted the Chinese luxury market successfully, enhancing the returning trend of Chinese luxury consumption. According to the official disclosure of China Central Television, since the implementation of Hainan's duty-free store policy, more than 280,000 shopping passengers have visited Hainan, and duty-free sales amounted to 2.219 billion yuan, which is 2.34 times over the same period last year [4]. According to the report of Yanqing He and Rulian Chen from the CITIC Research Institute, the domestic duty-free scale will exceed about RMB 50 billion in 2019 and is expected to exceed RMB 160 billion by 2025 , eventually reaching the size of RMB 200 billion [5].

What is certain is that as foreign epidemics continue to recur, the Chinese duty-free market will become more diversified. Consumer demand for duty-free products will rise, especially for consumers who originally tend to buy entry-level luxury goods such as beauty and perfume when traveling abroad. Most luxury brands are currently facing the blow of a significant decrease in the number of Chinese tourists in the overseas market, which consumer group will be more sensitive to price factors than others. Domestic duty-free stores may become the new destination for Chinese tourists who cannot purchase luxury abroad. The duty-free store is a globally competitive business, as it is crucial for consumers to know where they can buy their target products at a good price, which is closely linked to the bargaining power of the operators. China's duty-free policy and the returning trend of Chinese luxury consumption means that luxury brands should put more effort into developing the Chinese market.

\subsection{Disruptive Innovative Marketing Strategy: Celebrity Endorsements}

The Chinese luxury market experienced a brief winter period from 2012 to 2014, when endorsements of luxury brands were mainly successful artists with excellent works and reputations. For example, actress $\mathrm{Li}$ Bingbing became the brand ambassador of Gucci in 2003 due to her outstanding acting career and international influence. The discreet endorsement choice of luxury brands reflects the conservative attitude and the protection of their brand image. However, with the rapid development of social media and the rise of the fan economy, the huge profit and value brought by young idols and celebrities have risen sharply. Though these young idols and celebrities, who are famous for their appearances and gossips, fail to match the brand tone, luxury brands still covet the consumption potential of their huge Generation $\mathrm{Z}$ fan base. However, most luxury brands did not act out of concern for the reputation of the luxury world as a whole.

Burberry embarked on a disruptive innovative marketing strategy by taking the first step in cooperating with idols and celebrities. Kris Wu became Burberry's first non-British ambassador and walked for the show in October 2016. Stimulated by the star effect, Burberry's sales in the third quarter of 2016 soared by 25 percent, and Kris Wu was regarded by overseas media as the biggest contributor to the brand's performance growth. In 2017, Angelababy became the first brand ambassador of Dior in China. The appointment news released by Dior's Weibo accounted for more than 380,000 reposts in just a few hours. Through the gradual expansion of the celebrity endorsement team, the number of Dior Weibo fans has soared from 1.79 million to 6.56 million in just four years, becoming one of the most popular luxury brands among Chinese consumers. According to the estimation of Morgan Stanley, Dior's sales in 2019 increased by 18.7 percent to 6.3 billion euros. After the huge success of Dior, this disruptive innovative marketing strategy formula was madly copied by more luxury brands, seeking cooperation with young celebrities and idols actively for the Chinese market. The situation has begun to get out of control, as the selection standard of luxury brand ambassadors has become lower and lower.

On January 19, 2021, Prada announced the termination of cooperation with Shuang Zheng due to her surrogacy and abandonment scandal, which cooperation only lasted nine days. Later on July 20, Louis Vuitton announced to end the two-year partnership with its global ambassador Kris $\mathrm{Wu}$, after the police informed Kris of the rape charge. On August 13, as Zhehan Zhang's visit to the Yasukuni Shrine in Japan sparked a huge controversy, Japanese jewelry brand TASAKI decided to terminate its partnership with Zhehan Zhang, whose endorsement lasted no more than that 12 days. It is no exaggeration to conclude that the aura of celebrity endorsements has been wholly shattered after a series of scandals. Although the appointment of celebrity ambassadors has brought considerable short-term benefits to luxury brands, the marginal effect of this marketing strategy has diminished and posed unknowable risks. Though luxury brands have been well aware of the risks involved, the reason why they still bet on celebrities is that the Chinese market is rapidly gaining ground in the global luxury industry. The fierce market competition does not allow luxury brands to lose the Chinese market, while no other market is as dependent on celebrities as the Chinese market. According to the Celebrity Consumption 
Influence Report given by the CBN data, even during the epidemic, the amount of celebrity-led spending increased by 52.3 percent in just six months [6]. On the social accounts of luxury brands, the reposts and likes of celebrity-related updates are usually thousands of times higher than those of regular messages.

However, when almost all luxury brands have appointed celebrity ambassadors, the return on investment ratio of this disruptive innovative marketing strategy will drop significantly. To explain, the disruptive innovative strategy of appointing celebrity ambassadors successfully has opened the new market by turning non-customers into customers. Nonetheless, according to Christensen, it is challenging to design a sustainable strategy based on disruptive innovation, as the disrupting enterprises have to establish their business model and value system to maintain their sustainability and competitive advantages [7]. To illustrate, for a successful luxury brand like Dior, when an approach becomes a replicable formula, it means the brand has to innovate its strategies. With the high endorsement fees caused by the blind pursuit of celebrity endorsers, luxury brands need to consider marketing expenses as well as the cost of maintaining the celebrity effect.

On this basis, the Chinese luxury market, which currently develops faster than the global market, tends to be the first to enter the rational adjustment period. To cooperate more efficiently, luxury brands have to develop diversified forms of cooperation in addition to celebrity endorsements.

\subsection{Online Markets: E-Commerce Wars}

For a long time, the efforts of luxury brands for digitalization were limited to selling goods that couldn't be sold offline or putting fashion shows online that couldn't be enjoyed in person. In fact, the uninspired online experience is unattractive to the consumers compared to the in-person events. However, fashion brands have realized that creating an outstanding online experience for consumers during the epidemic is necessary. To explain, under China's strict quarantine policy, it is difficult for Chinese consumers and media to undertake the price of weeks of isolation to attend fashion weeks and purchase luxuries overseas. Therefore, in order to attract Chinese consumers, luxury brands have placed their hopes on the online market instead of traditional marketing strategies, embracing digitalization completely. Taking Chanel, who has always been cautious about digitalization as an example, the famous luxury brand collaborated with Chinese video site Tencent to live-stream its fashion show for the first time. Tencent's local experience helped Chanel achieve huge success, as the live viewers of the show reached 3.58 million, which is three times as many as that of Gucci and Prada.
The epidemic in early 2020 further reshaped the relationship between luxury brands and social media. The epidemic will eventually pass, while the impact of the epidemic on consumer behavior may be permanent, which means that the deep digitalization has benefits for the long-term development of luxury brands. On the premise that the epidemic may continue to be prolonged, powerful luxury brands should see this as an important opportunity to accelerate their online market presence and digital innovation. With the advent of the $5 \mathrm{G}$ era, online shopping may become the mainstream of luxury consumptions. As the epidemic becomes unpredictable, fashion brands need to seize every opportunity to face the future reshuffle in the industry.

\section{CONCLUSION}

Due to the continuous evolution of the coronavirus, the influence of the epidemic will likely continue to reverberate through the luxury industry in 2022. The epidemic crisis offers an unprecedented opportunity for the luxury industry to develop itself for long-term growth in China. From the perspective of the global market, the outbreak exposes long-standing operational weaknesses in the industry. As overseas markets need more time to recover and rebuild, luxury brands need to tap into new customer segments in the booming Chinese market for profitable growth. It is also essential for luxury brands to realize that the impact of the outbreak on consumer habits could be long-lasting. Hence, by constructing the maturing digital channels in the Chinese market, luxury brands should develop sustainable innovative strategies to appeal to both the material and emotional values of the returning Chinese middle-income consumer group and the emerging Chinese Generation $\mathrm{Z}$ consumers, capturing the market share for the future expansion.

The next step of my research will focus on several aftermaths brought by the continuous expansion of luxury brands, as their efforts and investments in the market will eventually become brand premiums. Indeed, during the epidemic, more luxury brands have introduced a regular price increase model to supplement their expansions, which set a trap for their long-term development. At the same time, the increasing prices of luxuries give Chinese local fashion brands growth opportunities, which products are more affordable for Generation Z customers. Moreover, Chinese local fashion brands have expressed strong abilities to achieve customers' resonance and emotional value with a deep understanding of Chinese culture. As this research fails to demonstrate the unstoppable growing trend of Chinese local fashion brands, the author will mainly focus on both internal and external defects in the development of luxury industries in the future. 


\section{ACKNOWLEDGMENT}

This research was partially supported by Dr. Kishore Sengupta from the University of Cambridge, who sincerely shared his great insight and precious experience to assist the research significantly, although any errors in this paper should not stain the reputation of this esteemed person. Dr. Kishore Sengupta's professional knowledge about business innovation and marketing strategy immensely enhanced the manuscript.

\section{REFERENCES}

[1] Bain \& Company. (2015) 2014 China Luxury Market Study. https://www.bain.cn/pdfs/201501221159032010.p df.

[2] Zhou, T. (2017) The Future of the Luxury Market under the New Retail Format. https://www.sohu.com/a/128406210_114731.

[3] Lannes, B., \& Zhang, J. (2020) China Luxury Market in 2020: Unstoppable. https://www.bain.cn/pdfs/202012160240411747.p df.

[4] China Central Television. (2020) New policy for duty-free shopping in Hainan has been implemented for one month. http://tv.cctv.com/2020/08/02/VIDEhX7tG6Z5gOr A4XPTTnro200802.shtml.

[5] He, Y., \& Chen, R. (2020) In-depth Excavation of the Duty-free Market: A Golden Industry Protected by Policies, A Fast-growing Trillion-dollar Market. http://www.cs.ecitic.com/newsite/.

[6] Song, H. (2020) Celebrity Consumption Influence Report in the First Half of 2020. https://www.cbndata.com/information/82358.

[7] Christensen, C. M., Raynor, M., \& McDonald, R. (2015) What is disruptive innovation? https://hbr.org/2015/12/what-is-disrupt ive-innovation. 